\title{
Harmonics Reduction Techniques in Renewable Energy Interfacing Converters
}

\author{
Ali M. Eltamaly, Ph.D \\ King Saud University \\ Saudi Arabia
}

\section{Introduction}

In the recent years there has been growing interest in renewable energy generation along with growing demands for development of a suitable utility interface system. Low harmonics in the line currents of the converters used in the utility interface of the renewable energy system is the highest challenge. Controlled and uncontrolled converters are used widely in the utility interface of renewable energy systems to reduce cost, harmonic contents in line currents and to increase the reliability. These converters suffer from high level of Total Harmonic Distortion (THD) in the utility line currents which creates a lot of problems in the power system. A detailed third harmonic current injection technique has been introduced in details to reduce the harmonic contents in line currents of controlled and uncontrolled converters that used in renewable energy applications. The approach is based on circulating third harmonic current from DC link current to line currents of controlled and uncontrolled converters to reduce its THD. A new injected current shape is computed from analysis to achieve sinusoidal utility line currents. A controllable single switch boost converter connected in shunt is employed to circulate the new injected current shape. A method to implement the proposed approach under varying load condition is shown. Analysis, design, limitations, simulation and experimental result are presented.

In modern power electronics converters, three-phase controlled converter is commonly used especially as a rectifier or as an inverter in interfacing renewable energy systems with electric utility (Naik et al., 1995; Mohan, 1992, and Eltamaly, 2008). Three-phase controlled converter has simple construction and control, low cost, and low acoustic noise compared with other solutions like a full-bridge IGBT line side inverters or with Vienna rectifiers. Line current of controlled converter and its FFT components are shown in Fig. 1. It is clear from this waveform that this converter generates high harmonics in the line currents which distort the voltage at the point of common coupling in the power system. A lot of efforts have been performed to reduce harmonic contents in the utility line currents of controlled converter (Pacheco et al., 1994 - Arrillaga et al., 2006). Passive filters have been used in many researches with different configurations (Pacheco et al., 1994 and Bhattacharya et al., 1993), but this technique suffers from bulky, heavy filter elements and sometimes causes resonance problems. Active filters have been used in many researches and it sounds an 
interesting option but this technique suffers from complexity and high cost (Ortega et al., 2005 and Lin \& Ou, 2004). Hybrid solutions using active filters and passive filters in high power applications for improving passive filter performance (Bhattacharya et al., 1997). Increasing number of pulses (Lee et al., 1997 - Tinsley, 2003) reduces the harmonic contents in line current but this technique needs large in size, heavy in weight, high in cost, complex construction, and it will not be ready available from manufacturer (Lee, 1998). Early work in third harmonics injection techniques have been used in (Mohan, 1992 \& Bhattacharya et al., 1993 and Arrillaga et al., 2006). Some other literatures use switches in the main pass of power flow which increase the switching losses and reduce the system reliability (Naik et al., 1995). Injection of third harmonic current to line currents can be achieved by using LC branches tuned around third harmonic frequency (Arrillaga et al., 2006). But, this scheme suffers from bulky construction, resonant problems, and the current in the injection branch is very sensitive to the deviation of $\mathrm{L}$ and $\mathrm{C}$ values. Most of three phase line current harmonics reduction techniques are summarized in (Mao et al., 19987 and Singh et al., 2004). Injection of third harmonic to line current using zigzag transformer has been shown in many researches and (Naik et al., 1995 and Pejovic, 2000). These researches and the ideas shown in this research show the superiority of this technique in reducing the harmonic contents of line currents and increasing the power factor of the controlled or uncontrolled converters.

\section{Proposed Approach}

Figure 2 shows the topology of the proposed approach to reduce harmonics generated by line commutated thyristor inverter used in interfacing renewable energy sources with electric utility. This approach contains a zigzag transformer that presents high impedance for fundamental frequency component and very low impedance for the injection current. A single-phase transformer is connected between the dc-link mid-point ' $\mathrm{o}$ ' and the zigzag transformer neutral ' $n$ '. The secondary of single-phase transformer is connected to a rectifier boost converter stage feeding the dc link. By operating single switch the injected current If can be regulated. The duty ratio of the boost converter is varying to control the injection current to be depending on the dc link voltage.
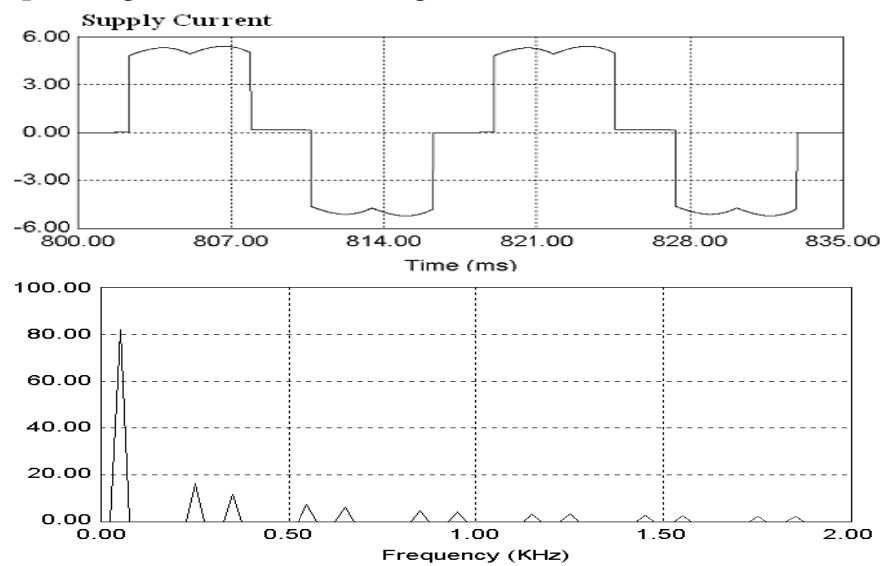

Fig. 1. Supply current and its FFT of controlled converter without harmonic reduction. 
The optimal rms value and phase angle of injection current to get the minimum THD of supply current is the main issue in this chapter. Previous results say; the best rms value of 3rd harmonic current is equal to the average value of dc link current (Choi et al., 1996 and Lee, 1998. But it is not the only condition required, however, the angle of injection current plays a very important rule in the THD of the line current. So, it is important to determine the relation between the angle of injection current and the firing angle $\alpha$.

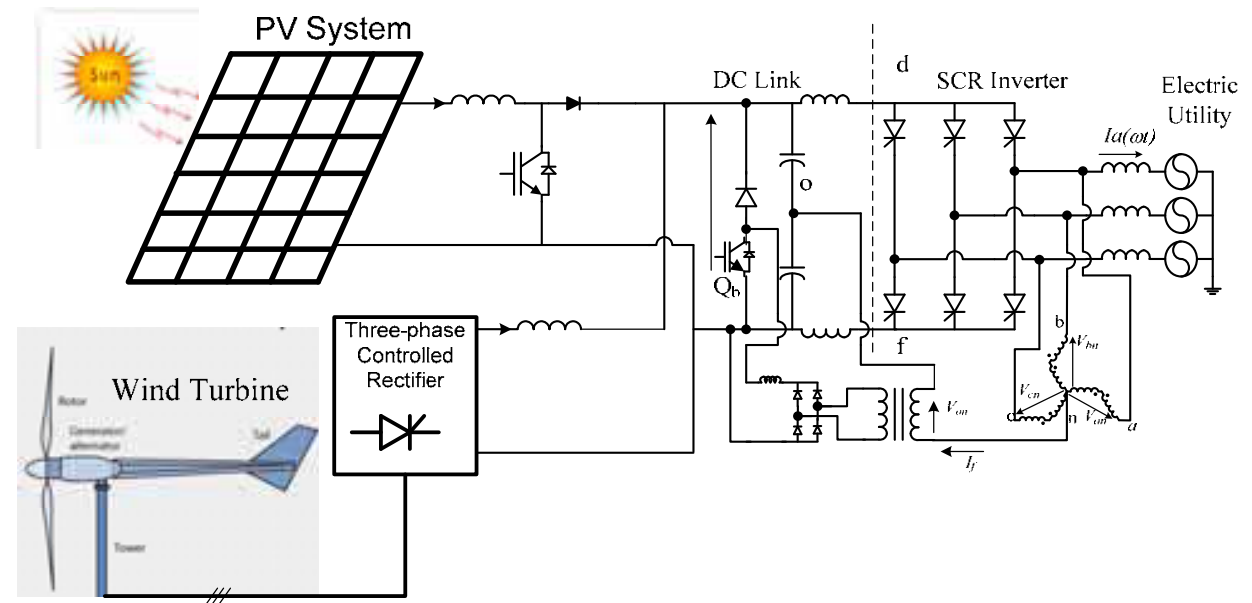

Fig. 2. The proposed approach

For firing angle $\alpha=20^{\circ}$ (as an example), Fig. 3 (a) shows the utility line current with respect to the voltage of phase ' $a$ '. In Fig. 3 (b), the $3^{\text {rd }}$ harmonic injection current with respect to phase $a$ voltage. It is clear from this waveform that the injection current leads the phase a voltage by $120^{\circ}$ which agree with the analysis and waveforms in the upcoming sections. In Fig. 3(c); the line current with using the $3^{\text {rd }}$ harmonic current along with the phase voltage $a$. This figure reveals that the angle between $I_{f}$ and $I_{a}$ must be $180^{\circ}$ with respect to $3^{\text {rd }}$ harmonic frequency. In Fig. 3(d) the voltage between point ' $d$ ' and ' $n$ ' $V_{d n}$, the voltage between point ' $f$ ' and ' $n$ ' $V_{f n}$ and the voltage between ' $o$ ' and ' $n$ ' $V_{o n}$ along with phase ' $a$ ' voltage. The third harmonic components of the voltages $V_{d n}, V_{f n}$ and $V_{o n}$ have been used to inject third harmonic back to utility line current to reduce the harmonic contents in utility line currents. So a careful analysis for these voltages is required to get the optimum value of injection current and its angle. It is convenient to employ Fourier series in the analysis of the distorted waveforms. In general, a non-sinusoidal waveform $f(\omega t)$ can be expressed as follows:

$$
f(\omega t)=a_{0}+\sum_{n=1}^{\infty}\left(a_{n} \quad \cos (n \omega t)+b_{n} \sin (n \omega t)\right)
$$

where $a_{0}, a_{n}$, and $b_{n}$ are Fourier coefficients.

By applying Fourier equations to the waveforms of $V_{d n}$ only to get the third harmonic component as following: 


$$
\begin{aligned}
& a_{3}=\frac{3}{\pi} \int_{\frac{\pi}{6}+\alpha}^{\frac{5 \pi}{6}+\alpha} V_{m} \sin \omega t^{*} \cos 3 \omega t d \omega t=\frac{3 \sqrt{3} V_{m}}{8 \pi}[2 \sin (2 \alpha)-\sin (4 \alpha)] \\
& b_{3}=\frac{3}{\pi} \int_{\frac{\pi}{6}+\alpha}^{\frac{5 \pi}{6}+\alpha} V_{m} \sin \omega t^{*} \sin 3 \omega t d \omega t=\frac{3 \sqrt{3} V_{m}}{8 \pi}[\cos (4 \alpha)-2 \cos (2 \alpha)]
\end{aligned}
$$

From (1) and (2), $V_{d n 3}$ and its angle can be obtained as in (3) and (4).

$$
V_{d n 3}=\frac{1}{\sqrt{2}} * \sqrt{a_{3}^{2}+b_{3}^{2}}=\frac{3 V_{L L}}{8 \pi} \sqrt{1+8 \sin ^{2} \alpha}
$$

where: $V_{m}$ is the peak value of phase voltage,

$V_{L L}$ is the rms value of line to line supply voltage, and,

$V_{d n 3}$ is the rms value of $3^{\text {rd }}$ harmonic of the voltage between points $d$ and $n$.

And angle of $V_{d n 3}$ is

$$
\tan ^{-1}\left(\frac{a_{3}}{b_{3}}\right)=\tan ^{-1}\left(\frac{2 \sin (2 \alpha)-\sin (4 \alpha)}{\cos (4 \alpha)-2 \cos (2 \alpha)}\right)
$$

In the same way $V_{f n 3}$ can be obtained as following:

$$
\begin{aligned}
& a_{3}=\frac{3}{\pi} \int_{\frac{7 \pi}{6}+\alpha}^{\frac{11 \pi}{6}+\alpha} V_{m} \sin \omega t^{*} \cos 3 \omega t d \omega t=\frac{3 \sqrt{3} V_{m}}{8 \pi}[2 \sin (2 \alpha)-\sin (4 \alpha)] \\
& b_{3}=\frac{3}{\pi} \int_{\frac{7 \pi}{6}+\alpha}^{11 \frac{5 \pi}{6}+\alpha} V_{m} \sin \omega t^{*} \sin 3 \omega t d \omega t=\frac{3 \sqrt{3} V_{m}}{8 \pi}[\cos (4 \alpha)-2 \cos (2 \alpha)]
\end{aligned}
$$

From (5) and (6), $V_{f n 3}$ and its angle as in (7) and (8).

$$
V_{f n 3}=\frac{1}{\sqrt{2}} * \sqrt{a_{3}^{2}+b_{3}^{2}}=\frac{3 V_{L L}}{8 \pi} \sqrt{1+8 \sin ^{2} \alpha}
$$

$V_{f n 3}$ is the rms value of $3^{\text {rd }}$ harmonic of the voltage between points $f$ and $n$.

And angle of $V_{f n 3}$ is;

$$
\begin{gathered}
\tan ^{-1}\left(\frac{a_{3}}{b_{3}}\right)=\tan ^{-1}\left(\frac{2 \sin (2 \alpha)-\sin (4 \alpha)}{\cos (4 \alpha)-2 \cos (2 \alpha)}\right) \\
V_{\text {on } 3}=\frac{V_{d n 3}+V_{f n 3}}{2}
\end{gathered}
$$


Then;

$$
V_{\text {on } 3}=\frac{3 V_{L L}}{8 \pi} \sqrt{1+8 \sin ^{2} \alpha}
$$

And angle of $V_{o n 3}$, is

$$
\theta=\tan ^{-1}\left(\frac{a_{3}}{b_{3}}\right)=\tan ^{-1}\left(\frac{2 \sin (2 \alpha)-\sin (4 \alpha)}{\cos (4 \alpha)-2 \cos (2 \alpha)}\right)
$$

The $3^{\text {rd }}$ harmonic injection current is;

$$
I_{f} \angle \varphi=\frac{V_{\text {on } 3} \angle \theta}{Z \angle \psi}=\frac{V_{\text {on } 3}}{Z} \angle(\theta-\psi)
$$

where, $V_{\text {on } 3}$ is the rms value of $3^{\text {rd }}$ harmonic of the voltage between points $o$ and $n$, and, $\theta$ is the angle of $V_{\text {on } 3}$, and, $\psi$ is the angle between $V_{\text {on } 3}$ and $I_{f}$ (the impedance angle of injection current path).

As shown in Fig. 3, the voltage $V_{a}$ is taken as a reference, so the phase angle of fundamental and $3^{\text {rd }}$ harmonic components of phase $a$ current are $-\alpha$ and $-3 \alpha$ respectively. As explained in (Eltamaly, 2003) and it is clear from Fig. 3, the optimum phase difference between phase $a$ current and injection current is $180^{\circ}$. Then the difference between the angle of $I_{f}$ (which is $\phi$ ) and the angle of fundamental current which is $(-\alpha$ and $-3 \alpha$ for fundamental and third harmonic frequencies respectively) is $180^{\circ}$ as described in (13).

$$
\left(\varphi_{\text {opt }}\right)-(-3 \alpha)=180
$$

So the optimum angle of the injection current, $\phi_{\text {opt }}$ can be obtained from the following equation;

$$
\left(\varphi_{o p t}\right)=180-3 \alpha
$$

Also, the optimum angle of the impedance of injection current path, $\psi_{\text {opt }}$ can be obtained from the following equation;

$$
\psi_{\text {opt }}=\theta+3 \alpha-180
$$

From (14) and (15) the phase difference between each vectors for various firing angles; $\alpha$ $=20^{\circ}$ and $40^{\circ}$ (as an example for rectifier mode) and $\alpha=130^{\circ}$ and $150^{\circ}$ (as an example for inverter mode) is shown in Fig. 4 (a) and (b) respectively. From (10) the relation between $V_{o n 3} / V_{L L}$ and the firing angle $\alpha$ is shown in Fig. 5. In the same way; from (14) and (15) the variation of injection current optimum angle, the angle of $V_{o n 3}, \theta$ and the angle between $I_{f}$, and $V_{\text {on } 3}$ (angle of impedance angle of injection path) along with the firing angle $\alpha$ is shown in Fig. 5. 


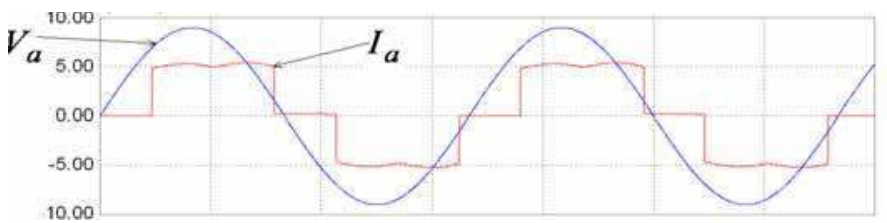

(a) Voltage and current of phase a.

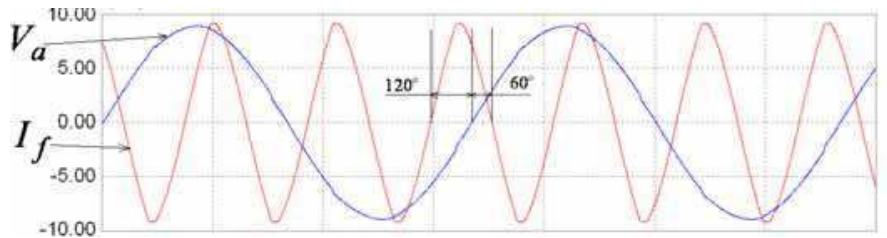

(b) Voltage of phase a and reinjection current.

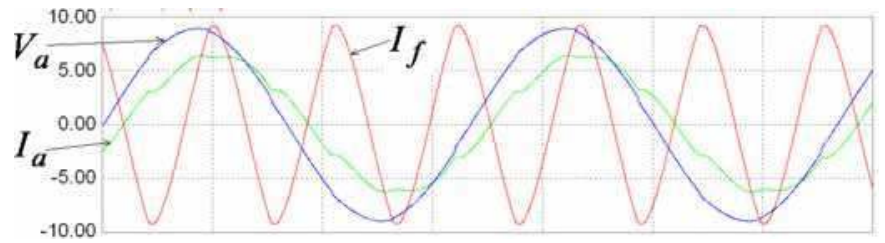

(c) Voltage, current of phase a and reinjection current.

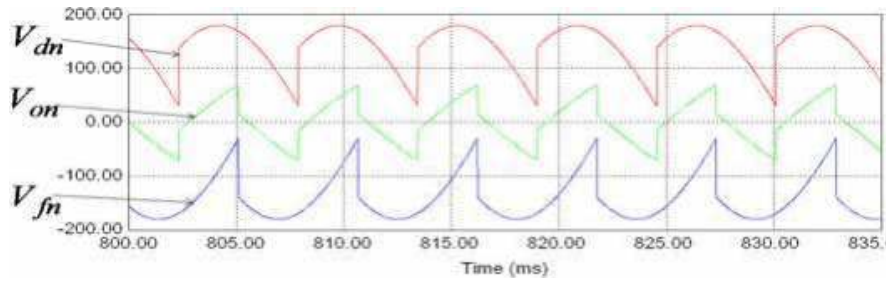

(d) The voltages $V_{d n}, V_{o n}$, and $V_{f n}$.

Fig. 3. Various voltages and currents of the proposed approach at $\alpha=20^{\circ}$.

\section{Design Example}

Experimental and simulation verification for this technique has been carried out. The prototype model is used in simulation and in the experiment. DC link is connected to threephase controlled converter and electrical utility as shown in Fig. 2. For the controlled rectifier, the values of $V_{\text {on } 3}$ varies between $V_{\text {on3 }}(\alpha=0)=0.1194 \mathrm{pu}$ to $V_{\text {on } 3}\left(\alpha=90^{\circ}\right)=0.358 \mathrm{pu}$. At full load the dc current $I_{0}=0.6224 \mathrm{pu}$. The base voltage and current are $220 \mathrm{~V}$ and $3.3 \mathrm{~A}$, respectively.

The simulation results in the next section reveals that the minimum THD occurs almost at $I_{f} / I_{0}=1.15$, so at full load; $I_{f}=0.716 \mathrm{pu}$. The rated third harmonic current passing through zigzag transformer is $I_{f} / 3=0.239 \mathrm{pu}$. The value of $I_{f}$ is controlled depending on the value of dc link current for minimum THD. The third harmonic injection current can be controlled by controlling the duty ratio of the boost converter. Current sensor is used to measure the 
actual dc link current and the $3^{\text {rd }}$ harmonic injection current. The error signal between these two currents is used to control the duty ratio of the boost converter. $10 \mathrm{kHz}$ switching frequency of the boost converter is used in simulation and in the practical prototype. The schematic of the controlled circuit of the boost converter is shown in Fig. 6.

\section{Design of Single-Phase Transformer}

The rated primary voltage of single phase transformer in $3^{\text {rd }}$ harmonic injection pass is $V_{\text {on } 3}(\alpha=90)=0.358 \mathrm{pu}$. Also the rated primary current of this transformer is $I_{f}=0.716 \mathrm{pu}$. So, the rated $\mathrm{kVA}$ of this transformer is $0.716^{*} 0.358=0.256 \mathrm{pu}$.

The turns ratio of step up single-phase must handle the minimum value as well as the maximum value of $V_{\text {on } 3}$. The minimum value of $V_{\text {on } 3}$ is at $\alpha=0$ which is $V_{\text {on3 }}(\alpha=0)=0.1194 \mathrm{pu}$. Then, the corresponding value of $V_{\text {on3 }}^{\prime}$ is:

$$
V_{\text {on3 }}^{\prime}(\alpha=0)=0.1194 / n \text { pu }
$$

The output dc voltage of single-phase diode rectifier, $V_{b i}$ is:

$$
V_{b i}=2 * \sqrt{2} * V_{o n}^{\prime} / \pi
$$

The minimum value of $V_{\text {on }}$ is corresponding on the maximum value of the duty ratio of boost converter. Assume the maximum allowable value of the duty ratio is 0.8 . Then the output voltage of the boost converter, $V_{b o}$ is:

$$
V_{b o}=V_{b i} /(1-D)
$$

Substitute the value of $V_{b i}$ from (17) into (18) and $D=0.8$, the following equation can be obtained:

$$
V_{b o}(D=0.8)=\left(2 * \sqrt{2} * V_{o n}^{\prime} / \pi\right) /(1-0.8)=\left(10 * \sqrt{2} * V_{o n}^{\prime}\right) / \pi
$$

The output voltage from the boost converter must equal the dc link voltage. The dc link voltage is kept constant at $1.15 \mathrm{pu}$ by controlling the firing angle of the controlled converter and the modulation index of PWM inverter. So, by equating (19) with 2.2pu, the following equation can be obtained:

$$
10 * \sqrt{2} * V_{o n 3}^{\prime} / \pi=2.2 p u \text {, }
$$

Then;

$$
V_{\text {on3 }}^{\prime}(\alpha=0)=2.2 * \pi /(10 \sqrt{2}) p u
$$

By equating the values of $V_{\text {on }}^{\prime}$ in (14) and (18), the following equation can be obtained:

$0.1194 / n=2.2 * \pi /(10 \sqrt{2})$

Then the turns ratio of the single-phase transformer is:

$$
n=10 \sqrt{2} * 0.1194 /(2.2 * \pi)=0.24
$$



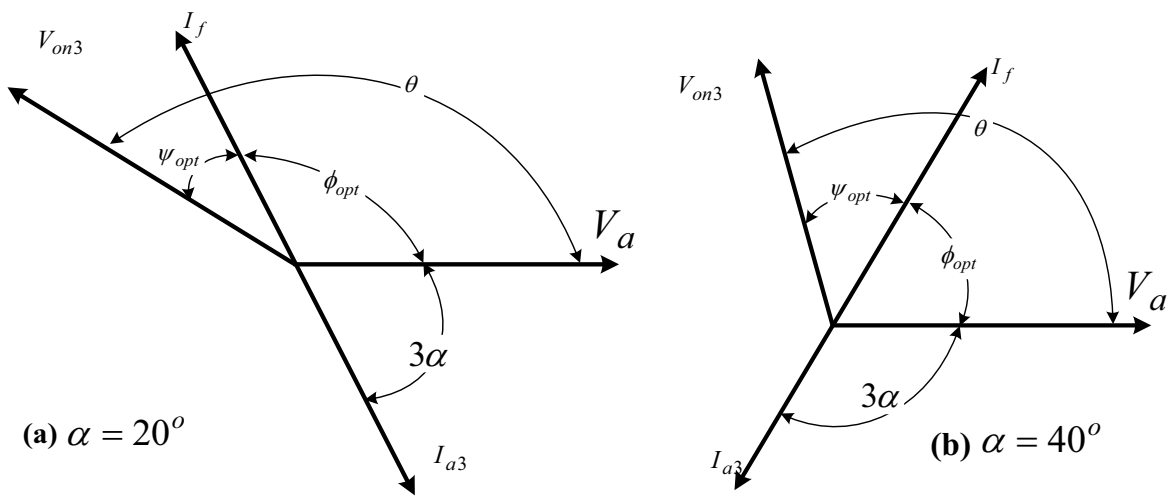

(a) Rectifier

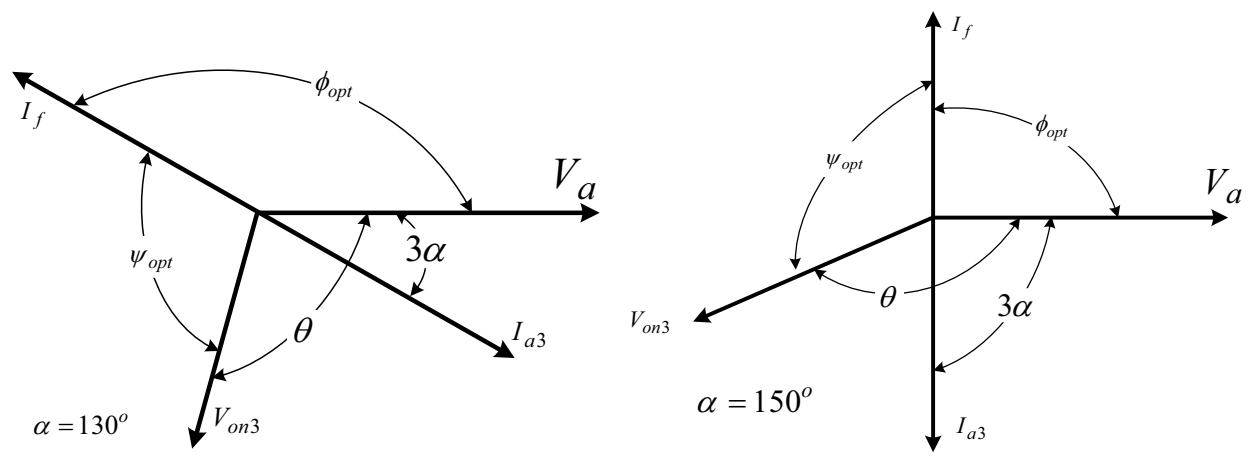

(b) Inverter

Fig. 4. Phase difference between each component in a rectifier and inverter 

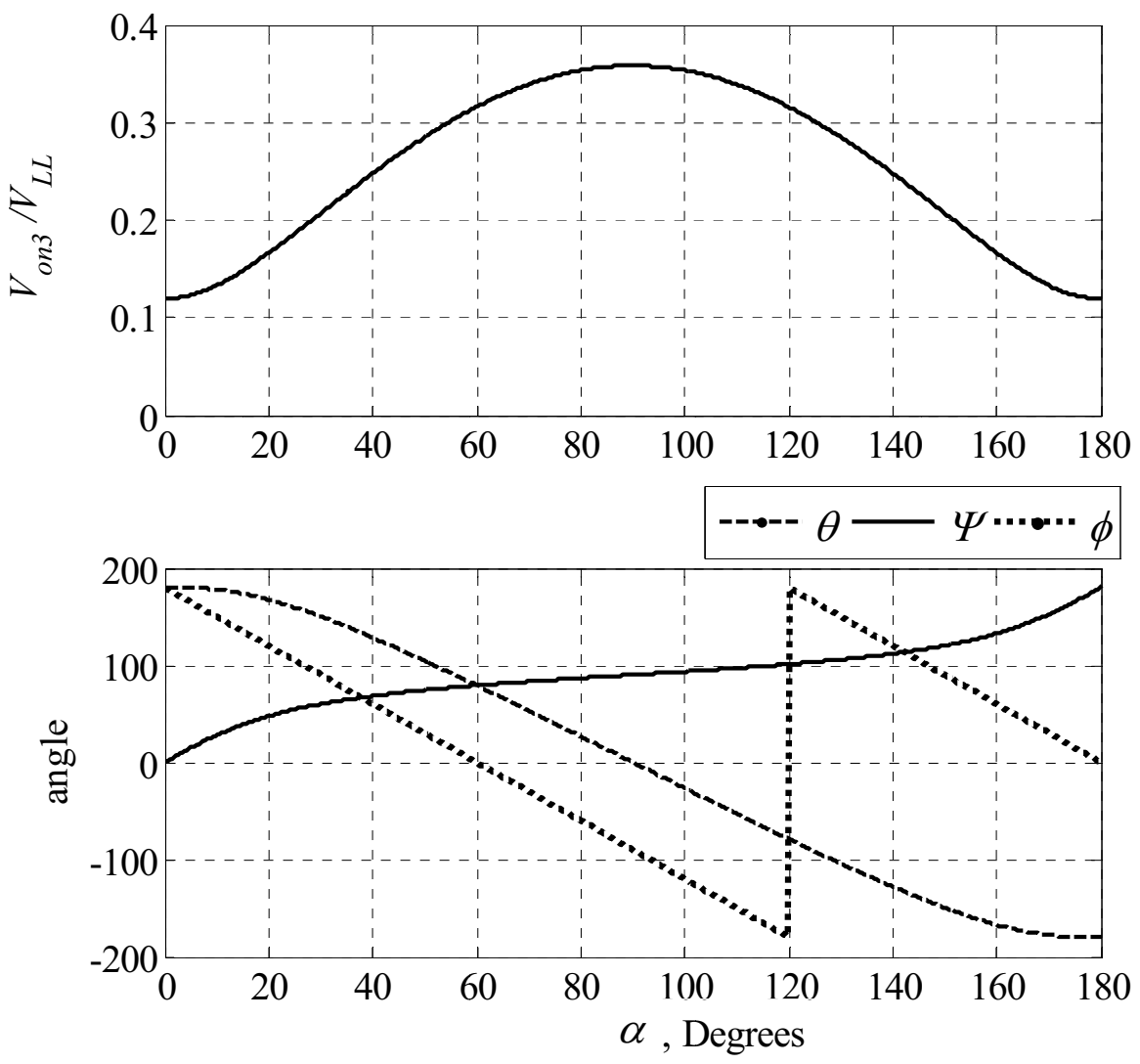

Fig. 5. The variation of $V_{o n 3}, \theta, \phi_{o p t}, \psi_{\text {opt }}$ along with $\alpha$.

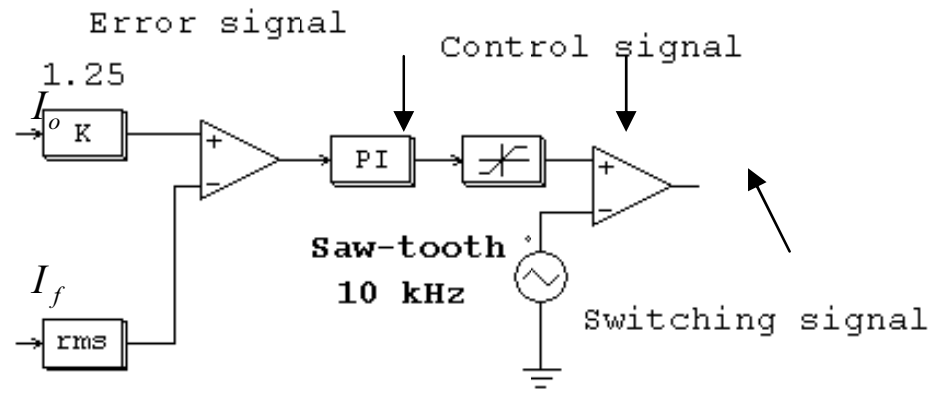

Fig. 6. The schematic of the control circuit of the boost converter. 


\section{Simulation and Experimental Results}

The simulation of the proposed technique has been performed by using PSIM computer program (PSIM6.1). Same values of the components used in simulation program have been used in the experimental prototype to compare these results.

Fig. 7 shows the relation between THD and the value of $I_{f} / I_{o}$ for different values of firing angle, $\alpha$. This figure reveals that the optimal value of $I_{f} / I_{o}$ is about 1.15 for the best THD. Also, This figure shows the importance of $3^{\text {rd }}$ harmonic injection technique especially for high value of firing angle, $\alpha$.

Fig. 8 shows the relation between THD and the angle of $I_{f}$ with respect to $V_{o n}, \psi$ at $I_{f} / I_{0}=1.15$ for different values of firing angle, $\alpha$. It is clear that the best THD occurs around $\psi_{\text {opt }}$ which obtained from (13). The value of $\psi_{\text {opt }}$ increase with increasing the firing angle $\alpha$.

The simulation and experimental waveforms are shown for $\alpha=20^{\circ}$ and $40^{\circ}$ as an examples.

\subsection{Simulation and experimental results at $\alpha=20^{\circ}$}

Figure 9 shows the waveforms of voltage $V_{d f}$ and $V_{a b}$. Fig. 10 shows the supply current waveform and its FFT components with respect to phase $a$ voltage without injection of $3^{\text {rd }}$ harmonic current. It is clear from this figure that the supply current has very high THD mostly of $5^{\text {th }}$ and $7^{\text {th }}$ harmonics. Fig. 11 shows the voltage of $V_{d n}$, and $V_{f n}$. It is shown in the top of the experimental result waveform that the frequency of this voltage is $180^{\circ}$ which is the $3^{\text {rd }}$ harmonic voltage and the value of rms voltage is 39.9 that can be obtained from (10) at $\alpha=20^{\circ}$. Figure 12 shows the supply current waveform and its FFT components with respect to phase $a$ voltage with optimum amplitude and angle of $3^{\text {rd }}$ harmonic current injection. It is clear from this figure that the supply current becomes very near to sine-wave with $5 \%$ THD.

Figure 13 shows supply current waveform $I_{a}$ and optimum value and angle of injection $3^{\text {rd }}$ harmonic current with respect to phase $a$ voltage. It is clear from these waveforms that the value of the angle between $I_{f}$ and $V_{a}$ is about $120^{\circ}$ and the angle between $I_{a}$ and $I_{f}$ is $180^{\circ}$ which agree with the vector diagram shown in Fig. 4 (a). 


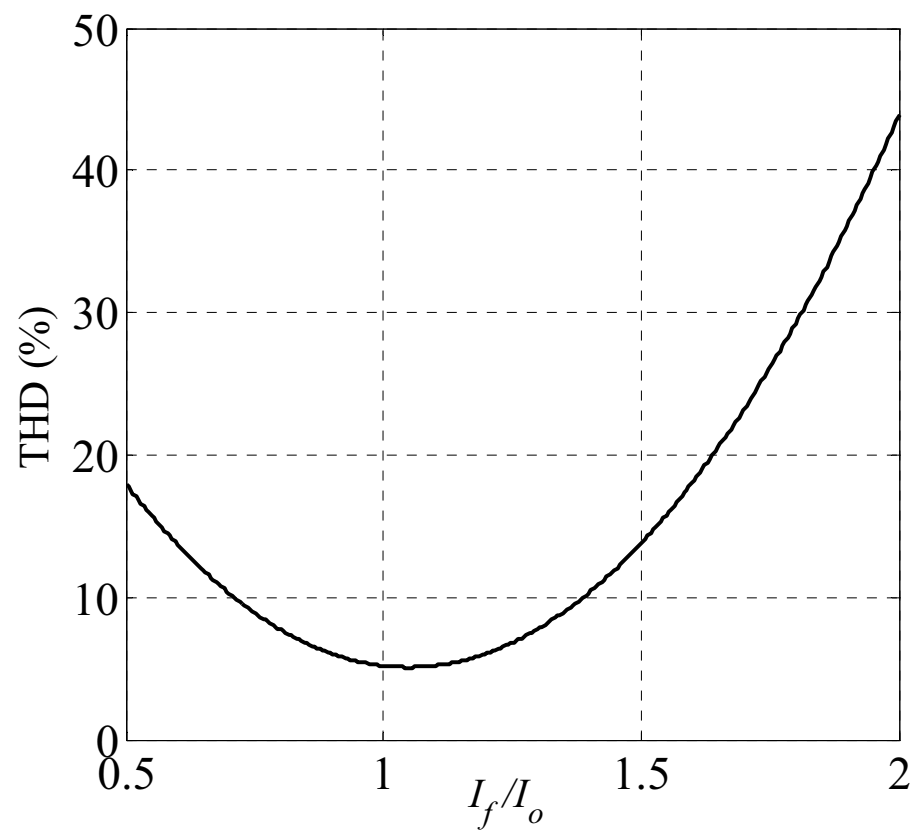

Fig. 7. The relation between THD and the value of $I_{f} / I_{0}$.

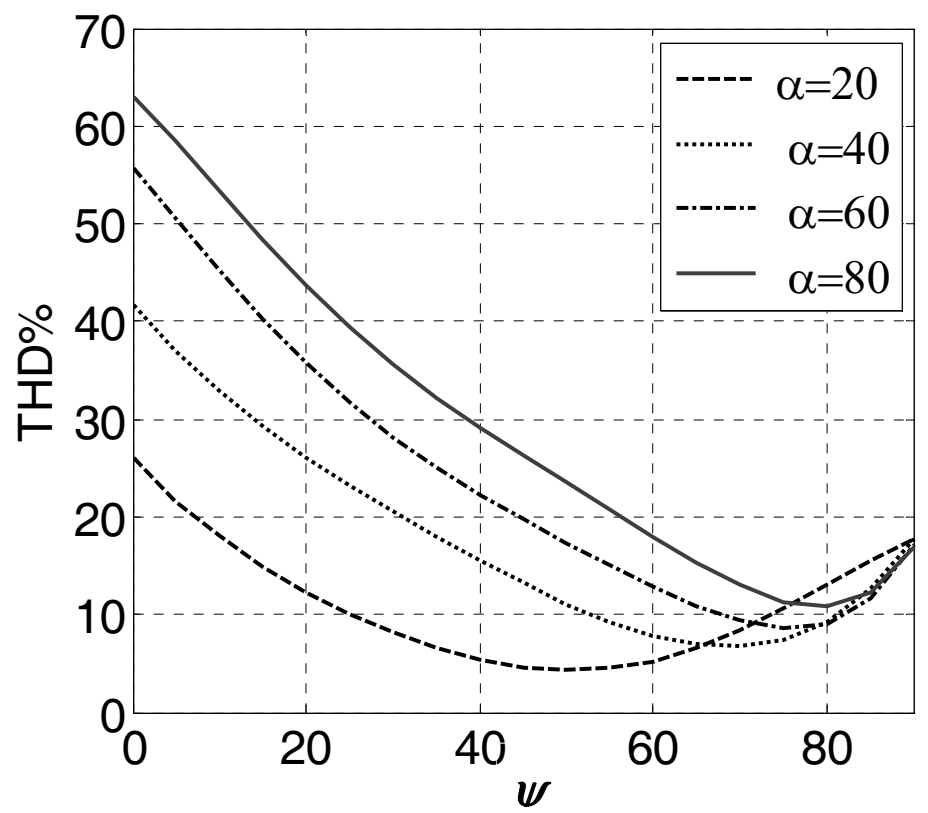

Fig. 8. The relation between THD and the angle of $I_{f}$ with respect to $V_{\text {on }}$ at $I_{f} / I_{0}=1.15$ for different values of firing angle, $\alpha$. 


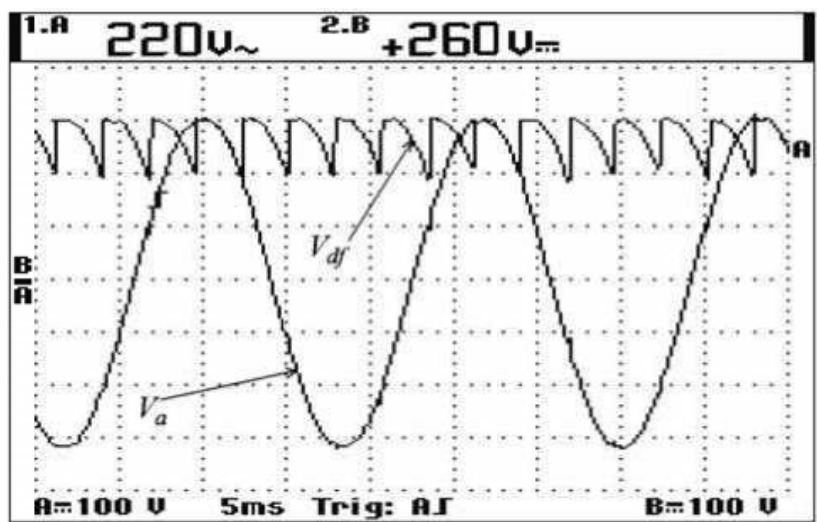

Fig. 9. The waveforms of voltage $V_{d f}$ and $V_{a b}$.

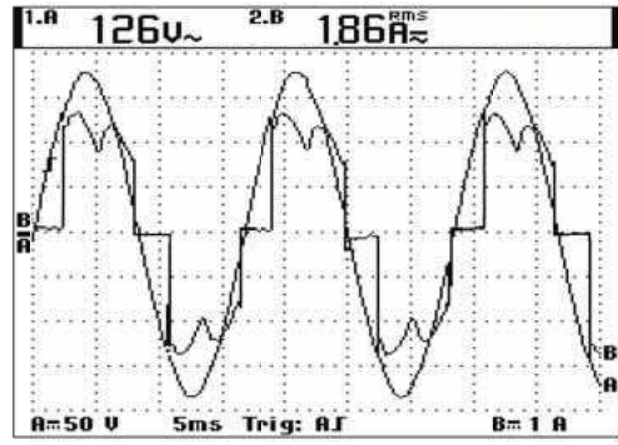

(a) Experimental result.

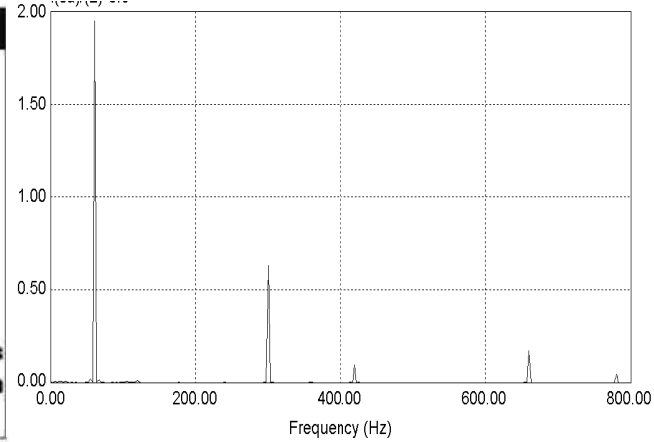

(b) FFT components of $I_{a}$

Fig. 10. The supply current waveform and its FFT components with respect to phase $a$ voltage without injection of $3^{\text {rd }}$ harmonic current.

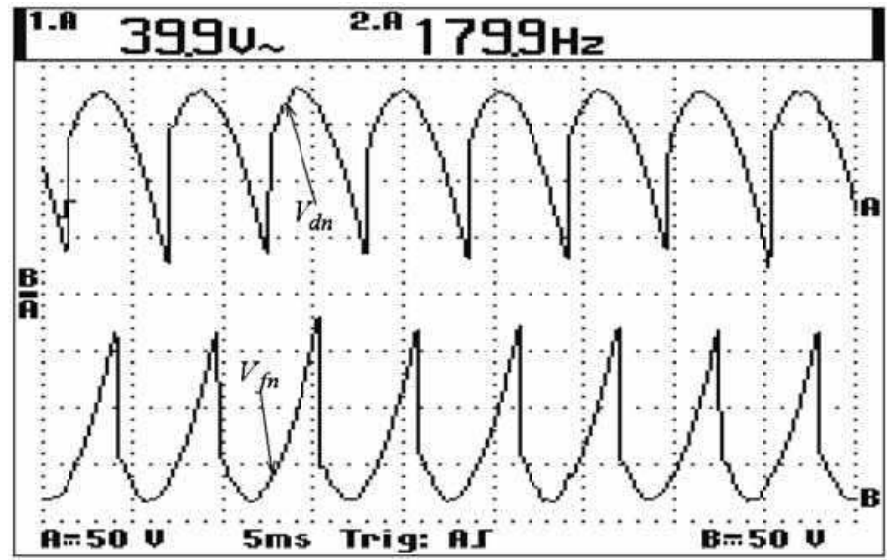

Fig. 11. The voltage of $V_{d n}$, and $V_{f n}$ 


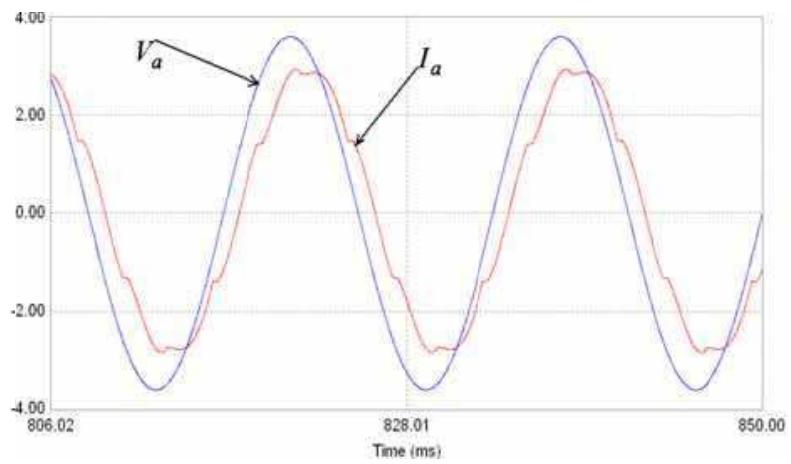

(a) Simulation result.

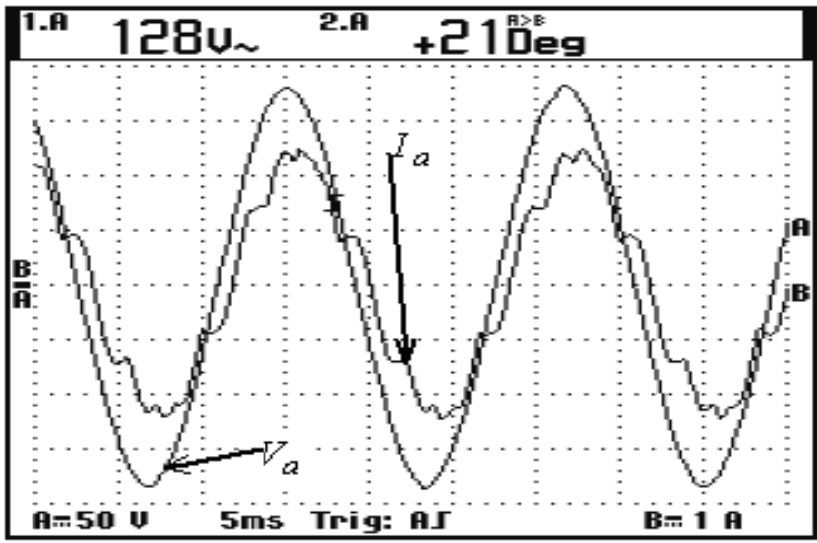

(b) Experimental result.

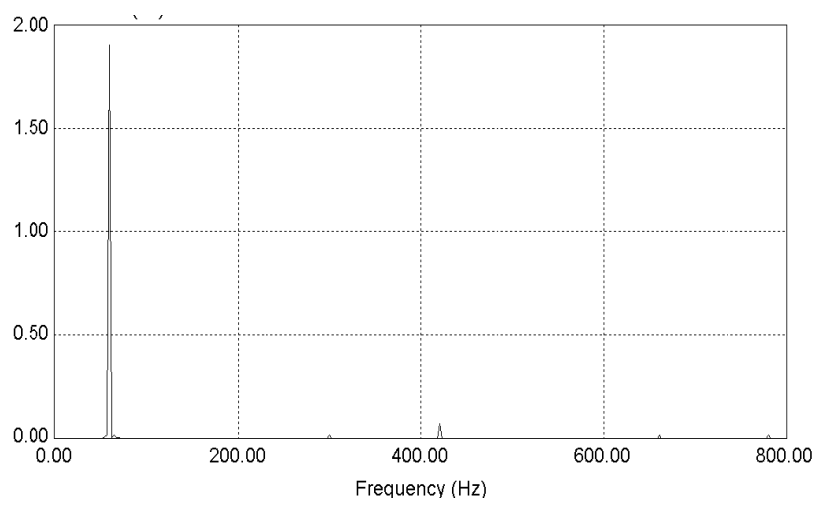

(c) FFT components of $I_{a}$.

Fig. 12. The supply current waveform and its FFT components with respect to phase $a$ voltage at optimum $3^{\text {rd }}$ harmonic current injection. 


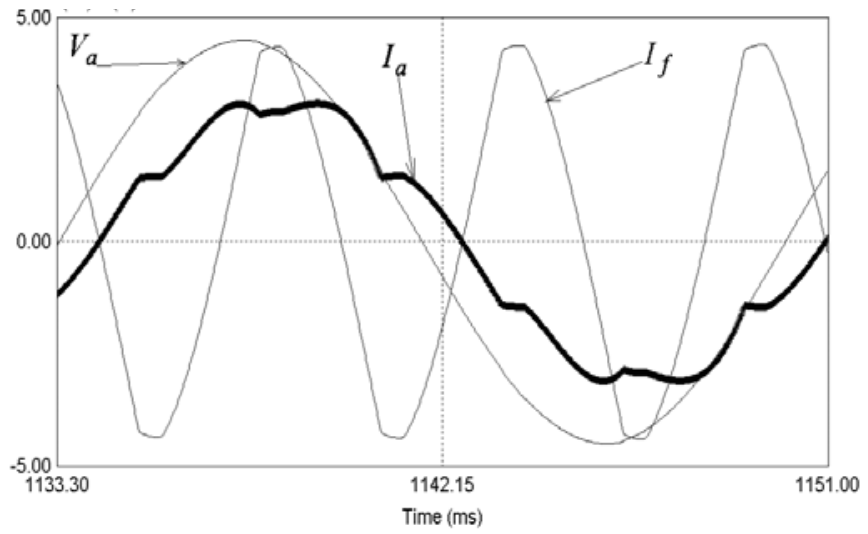

(a) Simulation result for $V_{a}$ and $I_{f}$.

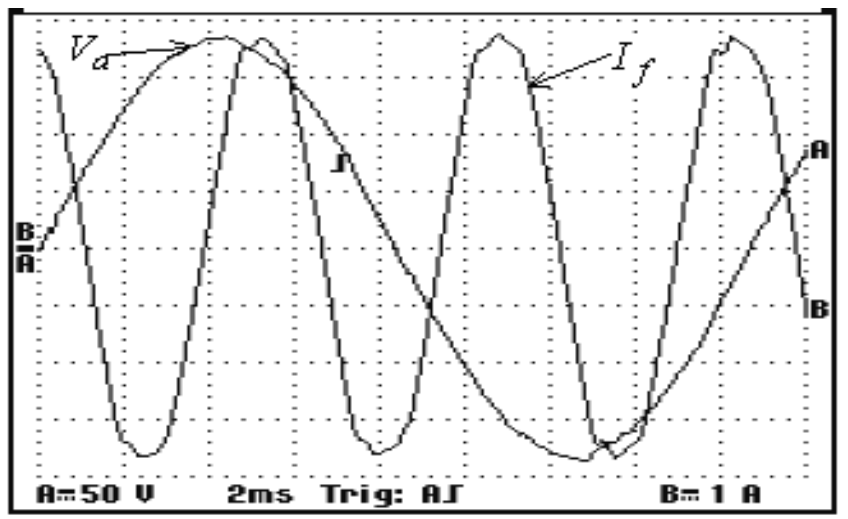

(b) Experimental result for $V_{a}$ and $I_{f}$.

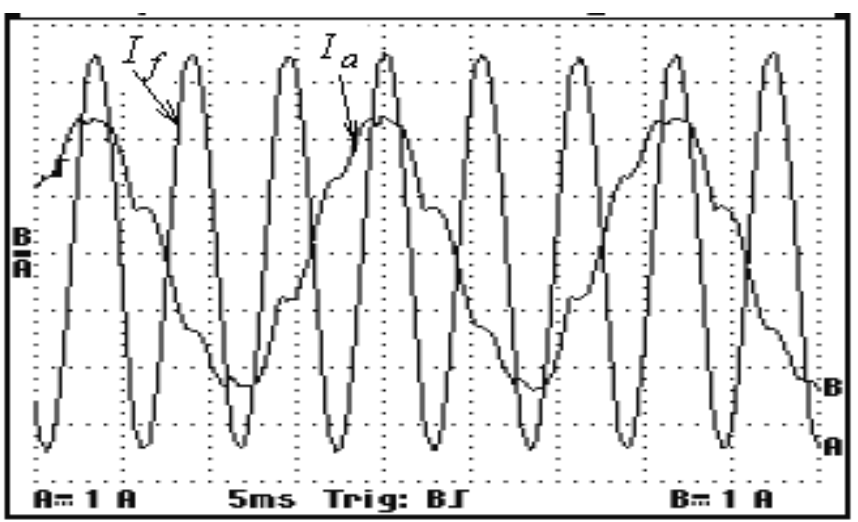

(c) Experimental result for $I_{a}$ and $I_{f}$

Fig. 13. The supply current waveform $I_{a}$ and optimum value and angle of injection $3^{\text {rd }}$ harmonic current with respect to phase $a$ voltage. 


\subsection{Simulation and experimental results at $\alpha=400$}

Figure 14 shows the waveforms of voltage $V_{d f}$ and $V_{a b}$. Fig. 15 shows the supply current waveform and its FFT components along with phase $a$ voltage without injection of $3^{\text {rd }}$ harmonic current. It is clear from this figure that the supply current has very high THD mostly of $5^{\text {th }}$ and $7^{\text {th }}$ harmonics. It is clear that this THD is high than the one of $\alpha=40$.

Figure 16 shows the voltage of $V_{d n}$, and $V_{f n}$ and their FFT components with respect to phase $a$ voltage. It is clear from this figure that these voltages have triplex harmonics and the $3^{\text {rd }}$ harmonic is the most dominant harmonic. It is also clear that both voltages $V_{d n}$, and $V_{f n}$ have the same harmonics.

Figure 17 shows supply current waveform and its FFT components with optimum value and angle of injection $3^{\text {rd }}$ harmonic current. It is clear from this figure that the supply current becomes very near to sine-wave with $6 \%$ THD.

Figure 18 shows the supply current waveform $I_{a}$ and optimum value and angle of $3^{\text {rd }}$ harmonic injection current with respect to phase $a$ voltage. It is clear from these waveforms that the angle between $I_{f}$ and $V_{a}$ is about $60^{\circ}$ which agree with the vector diagram in Fig. 4 (b).

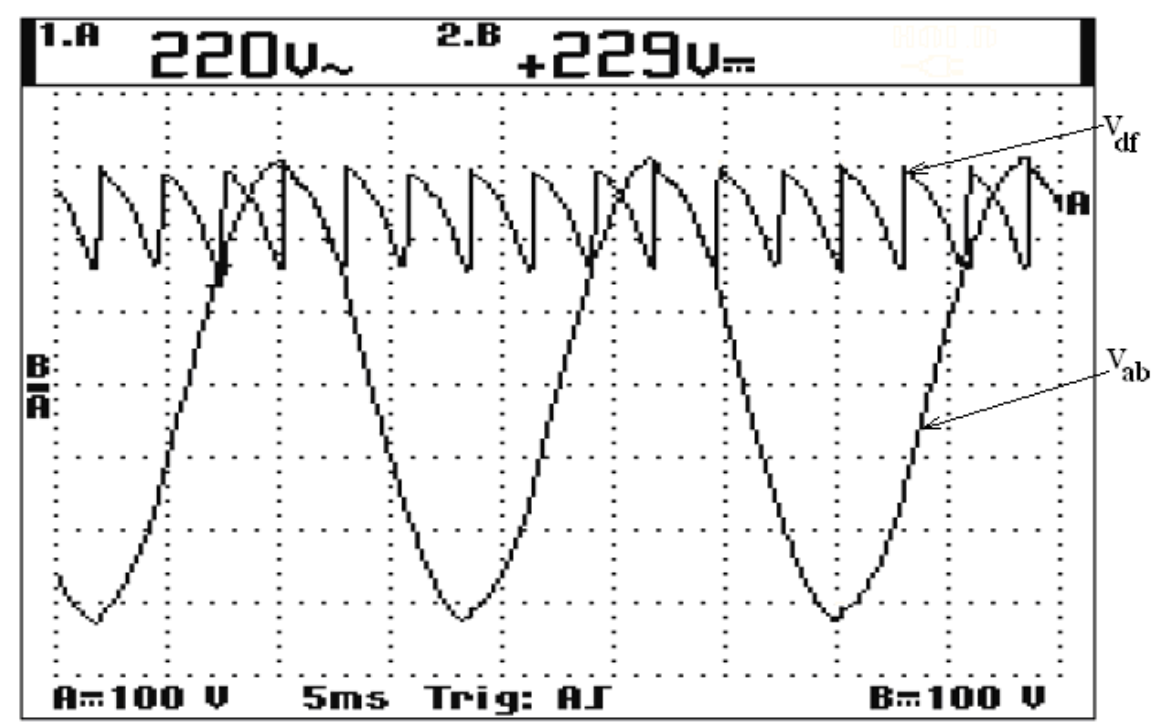

Fig. 14. The waveforms of voltage $V_{d f}$ and $V_{a b}$. 


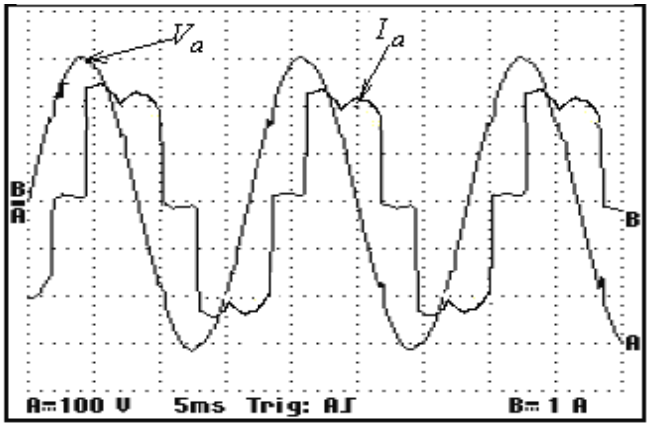

(a) Experimental result.

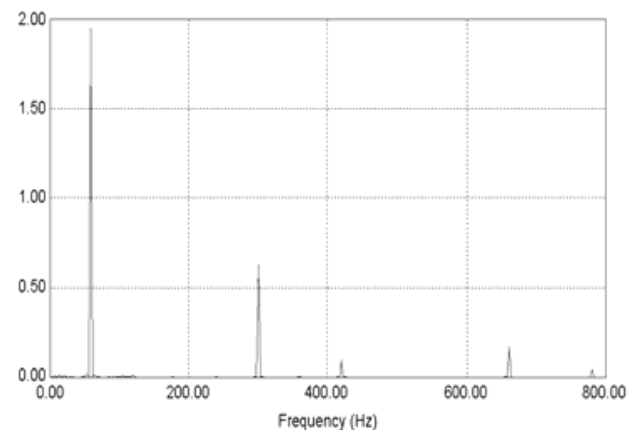

(b) FFT components of $I_{a}$

Fig. 15. The supply current waveform and its FFT components along with phase a voltage without injection of $3^{\text {rd }}$ harmonic current.

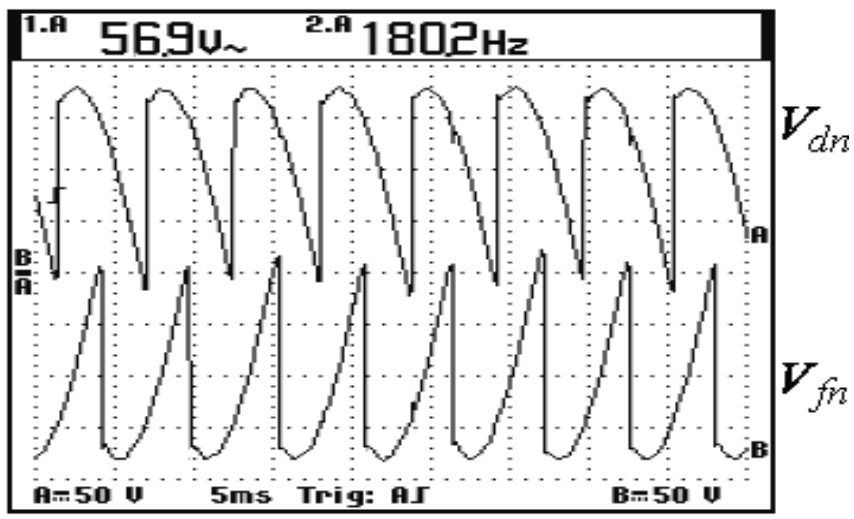

(a) Experimental result.

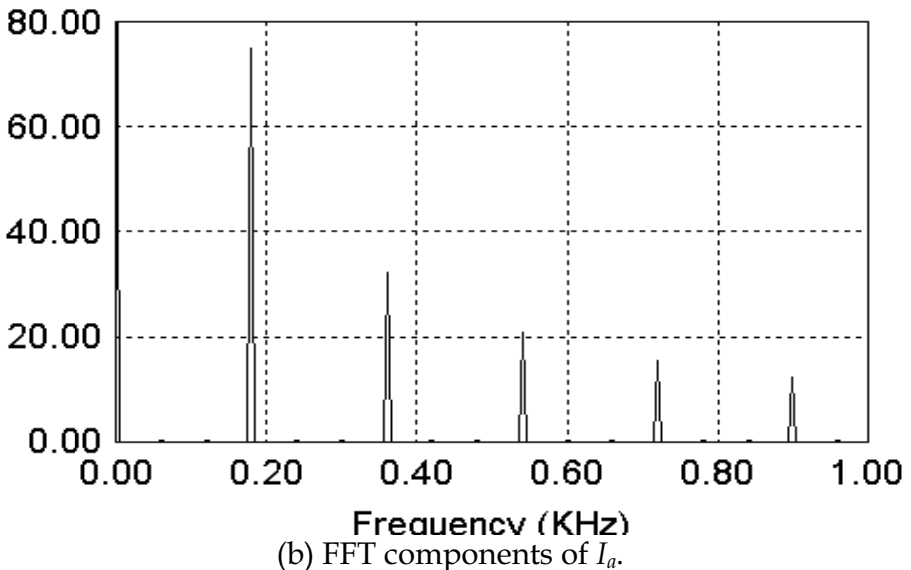

Fig. 16. The voltage of $V_{d n}$, and $V_{f n}$ and their FFT components with respect to phase $a$ voltage. 


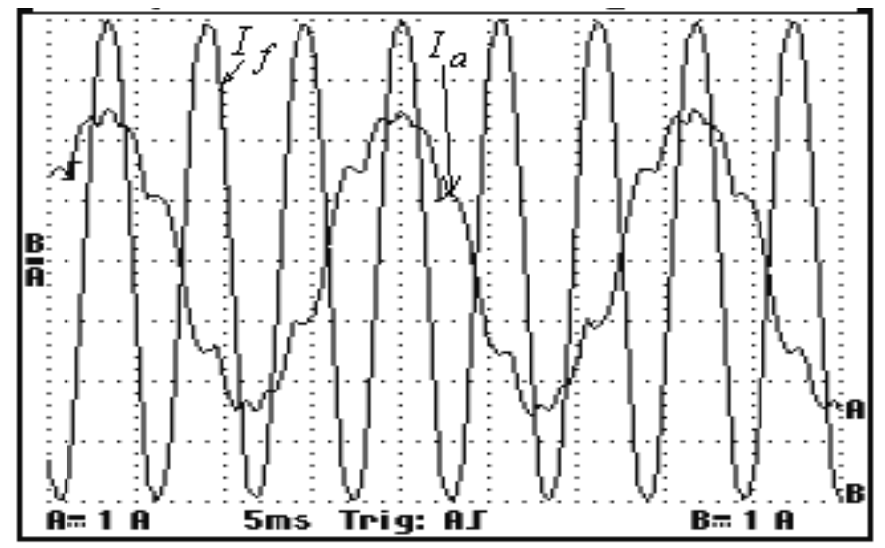

(a) Experimental result.

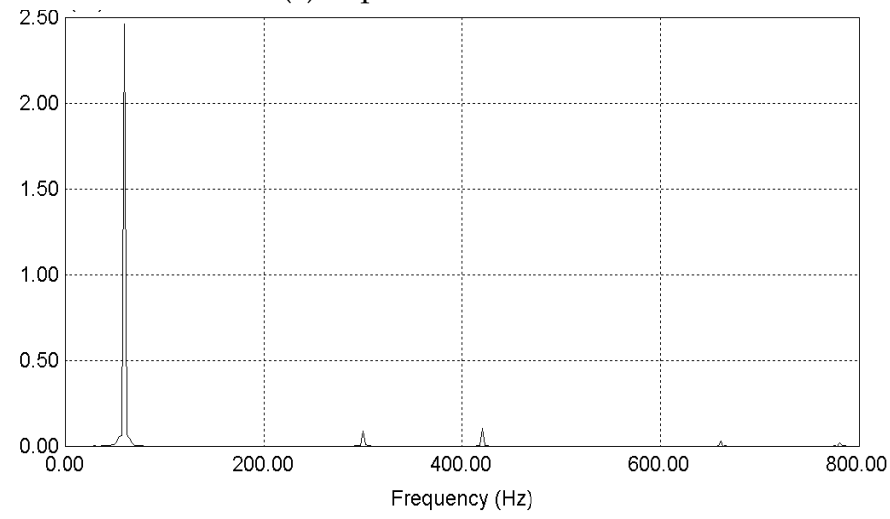

(b) FFT components of $I_{a}$.

Fig. 17. The supply current waveform and its FFT components with optimum value and angle of injection $3^{\text {rd }}$ harmonic current.

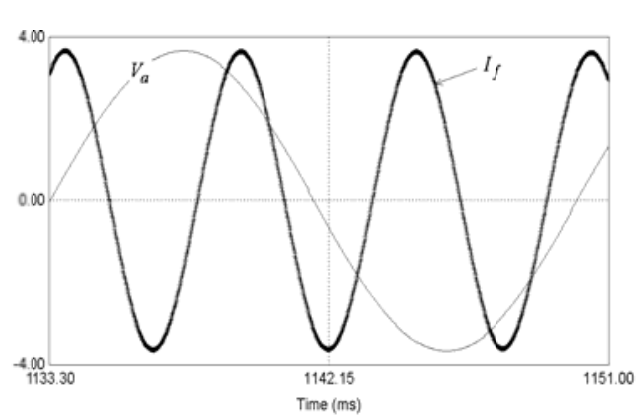

(a) Simulation result.

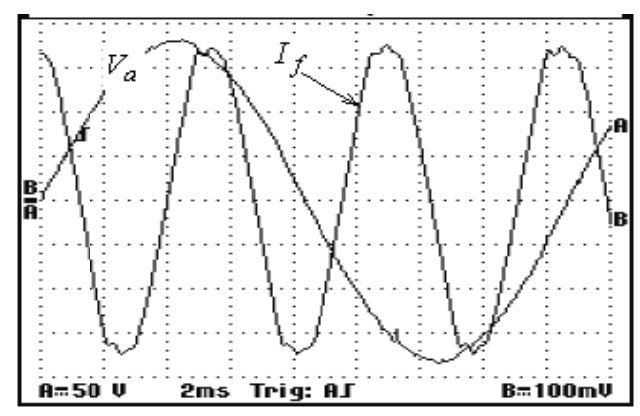

(b) Experimental result.

Fig. 18. The supply current waveform $I_{a}$ and optimum value and angle of injection $3^{\text {rd }}$ harmonic current with respect to phase $a$ voltage. 


\section{Conclusions}

Third harmonics injection technique plays a significant rule in reducing of the THD of the utility line current of three-phase controlled converters. The optimal amplitude and phase angle of injection current slightly changes with the firing angle. In this research, a detailed analysis for determining the relation between the optimal amplitude and phase angle of injection current along with the firing angle has been carried out. The THD of line current is highly affected by the amplitude of $3^{\text {rd }}$ harmonic injection current as well as its phase angle with supply voltage. The optimum amplitude and angle of $3^{\text {rd }}$ harmonic current have been determined by a detailed mathematical analysis of the system. The THD of the utility line current from simulation and the experimental results proves the mathematical results for this technique. The THD of the utility line current with optimal harmonic injection current is lower than limits of harmonics standards.

\section{References}

A. Ametani "Harmonic reduction in thyristor converters by harmonic current injection" IEEE Trans. on Power Apparatus and Systems, vol. PAS-95, no. 2 , March/April 1976, pp.441-450.

Ali M. Eltamaly "A Modified Harmonics Reduction Technique of Three-Phase Controlled Converter" IEEE Trans. Industrial Electronics, vol.55, No.3 March. 2008, pp. 11901198.

Ali M. Eltamaly" A new relation between firing angle of three-phase controlled converter and best angle of injection current " in IEEE Conf. Proc. MEPCON'2003, Minoufiya University, Shebin El-Kom, Egypt, Dec. 2003, pp. 793-798.

B. Lin, Y. Ou "Active power filter based on three-phase two-leg switch-clamped inverter" Electric Power Systems Research, vol. 72, June 2004, pp. 63-72.

B. S. Lee "New clean power reactor systems for utility interface of static converters", Ph.D. Thesis Texas AEM University, Aug. 1998.

B. S. Lee; P. N. Enjeti, I. J. Pitel “An optimized active interphase transformer for autoconnected 12-pulse rectifiers results in clean input power" in IEEE Conf. Proc. APEC1997, Atlanta, Georgia, USA, vol. 2, Feb. 1997, pp. 666-671.

Bhim Singh, Brij N. Singh, Ambrish Chandra, Kamal Al-Haddad, Ashish Pandey, Dwarka P. Kothari, "A review of three-phase improved power quality ac-dc converters" IEEE Trans. on Industrial Electronics, vol. 51, no. 3, June 2004.

C. T. Tinsley" Modeling of multi-pulse transformer rectifier units in power distribution systems" MS.c., Thesis Virginia Polytechnic Institute, USA, Aug. 2003.

Cassiano Rech, and José R. Pinheiro, "Line current harmonics reduction in multipulse connection of asymmetrically loaded rectifiers" IEEE Trans. on Industrial Electronics, vol. 52, no. 3, June 2005.

H. Mao, F. C. Y. Lee, D. Boroyevich, and S. Hiti, "Review of high-performance three-phase power-factor correction circuits" IEEE Trans. on Industrial Electronics, vol. 44, no.4, Aug. 1997, pp. 437-446.

H.A. Pacheco; G. Jimenez, J. Arau "Optimization method to design filters for harmonic current reduction in a three phase rectifier" in IEEE Conf. proc. CIEP'94, Puebla, Mexico, Aug. 1994, pp. 138-144. 
J. Marafao, J. Pomilio, and G. Spiazz " Improved three-phase high-quality rectifier with linecommutated switches" IEEE Trans. on Power Electronics, vol.19, no.3, May 2004, pp. 640-648.

J. Ortega, M. Esteve, M. Payán, A. Gómez "Reference current computation methods for active power filters: accuracy assessment in the frequency domain" IEEE Trans. on Power Electronics, vol. 20, no. 2, March 2005, pp. 446-456.

Jos Arrillaga, Y. H. Liu, Lasantha B. Perera, and Neville R. Watson "A current reinjection scheme that adds self-commutation and pulse multiplication to the thyristor converter" IEEE Trans. on Power Delivery, vol.21, no. 3, July 2006.

M. Rastogi, N. Mohan, and C. P. Henze " Three-phase sinusoidal current rectifier with zerocurrent switching" IEEE Trans. on Power Electronics, vol. 10, no. 6, Nov. 1995, pp. 753-759.

N. Mohan "A novel Approach to minimize line current harmonics in interfacing renewable energy sources with 3-phase utility systems" in IEEE Conf. Proc. APEC'92, Boston Massachusetts, Feb. 1992, pp. 852 -858.

N. Mohan, M. Rastogi and R. Naik " Analysis of a new power electronics interface with approximately sinusoidal 3-phase utility currents and a regulated dc output" IEEE Trans. on Power Delivery, April 1993, pp. 540-546.

P. Pejovic, D. Shmilovitz " Low-harmonic thyristor rectifiers applying current injection" IEEE TRANS. on Aerospace and Electronic Systems vol. 39, no. 4, Oct. 2003, pp.13651374.

P. Pejovic, P. Bojzovic, and D. Shmilovitz "Low-harmonic, three-phase rectifier that applies current injection and a passive resistance emulator" IEEE Power Electronics Letters, vol. 3, no. 3, Sept. 2005, pp. 96-100.

P. Pejovic" Two three-phase high power factor rectifiers that apply the third harmonic current injection and passive resistance emulation", IEEE Trans. on Power Electronics, vol. 15, no. 6, Nov. 2000, pp. 1228-1240.

PSIM6.1, available: www.powersimtech.com.

R. Naik, N. Mohan, M. Rogers and A. Bulawka" A novel grid interface, optimized for utility-scale applications of photovoltaic, wind-electric, and fuel-cell systems" IEEE Trns. on Power Delivery, vol.10, no.4, Oct. 1995, pp.1920-1926.

S. Bhattacharya, D. M. Divan; B. B. Banerjee; "Control and reduction of terminal voltage harmonic distortion (THD) in hybrid series active and parallel passive filter system" in IEEE Conf. Proc. PESC 93, Seatle, USA, June, 1993, pp. 779-786.

S. Bhattacharya, P. Cheng, and D. M. Divan, " Hybrid solutions for improving passive filter performance in high power applications" IEEE Trans. on Industry Applications, vol. 33, no. 3, May/June 1997, pp.732-747.

S. Choi, P. N. Enjeti, H. Lee, and I. I. Pital " A new active interface reactor 12-pulse rectifiers provides clean power utility interface "IEEE Trans. on Industry Applications, vol. 32, No. 6, 1996, pp. 1304-1311.

S. Pal "Simulation of current mode control schemes for power factor correction circuits" MS.c thesis, Faculty of Engineering and Applied Science, Mernorial University of Newfoundland, St. John's Newfoundland Canada, May 1998.

W. Mielczarski, W. B. Lawrance, R. Nowacki, and D. G. Holmes " Harmonic current reduction in three-phase bridge-rectifier circuits using controlled current injection" IEEE Trans. on Industrial Electronics, vol. 44, no. 5, Oct. 1997, pp. 604-611. 


\section{Renewable Energy}

Edited by $\mathrm{T} \mathrm{J}$ Hammons

ISBN 978-953-7619-52-7

Hard cover, 580 pages

Publisher InTech

Published online 01, December, 2009

Published in print edition December, 2009

Renewable Energy is energy generated from natural resources-such as sunlight, wind, rain, tides and geothermal heat-which are naturally replenished. In 2008 , about $18 \%$ of global final energy consumption came from renewables, with $13 \%$ coming from traditional biomass, such as wood burning. Hydroelectricity was the next largest renewable source, providing $3 \%$ (15\% of global electricity generation), followed by solar hot water/heating, which contributed with 1.3\%. Modern technologies, such as geothermal energy, wind power, solar power, and ocean energy together provided some $0.8 \%$ of final energy consumption. The book provides a forum for dissemination and exchange of up-to-date scientific information on theoretical, generic and applied areas of knowledge. The topics deal with new devices and circuits for energy systems, photovoltaic and solar thermal, wind energy systems, tidal and wave energy, fuel cell systems, bio energy and geo-energy, sustainable energy resources and systems, energy storage systems, energy market management and economics, off-grid isolated energy systems, energy in transportation systems, energy resources for portable electronics, intelligent energy power transmission, distribution and inter-connectors, energy efficient utilization, environmental issues, energy harvesting, nanotechnology in energy, policy issues on renewable energy, building design, power electronics in energy conversion, new materials for energy resources, and RF and magnetic field energy devices.

\section{How to reference}

In order to correctly reference this scholarly work, feel free to copy and paste the following:

Ali M. Eltamaly (2009). Harmonics Reduction Techniques in Renewable Energy Interfacing Converters, Renewable Energy, T J Hammons (Ed.), ISBN: 978-953-7619-52-7, InTech, Available from: http://www.intechopen.com/books/renewable-energy/harmonics-reduction-techniques-in-renewable-energyinterfacing-converters

\section{INTECH}

open science | open minds

\section{InTech Europe}

University Campus STeP Ri

Slavka Krautzeka 83/A

51000 Rijeka, Croatia

Phone: +385 (51) 770447

Fax: +385 (51) 686166

www.intechopen.com

\section{InTech China}

Unit 405, Office Block, Hotel Equatorial Shanghai

No.65, Yan An Road (West), Shanghai, 200040, China 中国上海市延安西路65号上海国际贵都大饭店办公楼405单元

Phone: +86-21-62489820

Fax: +86-21-62489821 
(C) 2009 The Author(s). Licensee IntechOpen. This chapter is distributed under the terms of the Creative Commons Attribution-NonCommercial-ShareAlike-3.0 License, which permits use, distribution and reproduction for non-commercial purposes, provided the original is properly cited and derivative works building on this content are distributed under the same license. 